\title{
Correction to: Latent Profiles and Grouping Effects of Resilience on Mental Health among Poor Children and Adolescents
}

\author{
Wenjie Duan ${ }^{1}$ (D) $\cdot$ Yujia Fei ${ }^{2} \cdot$ Xiaoqing Tang $^{3}$
}

Published online: 8 July 2019

(C) Springer Nature B.V. 2019

\section{Correction to: Child Indicators Research https://doi.org/10.1007/s12187-019-09637-3}

The original version of this article unfortunately contains incorrect affiliation of the corresponding author.

The corrected affiliation is presented below.

Publisher's Note Springer Nature remains neutral with regard to jurisdictional claims in published maps and institutional affiliations.

The online version of the original article can be found at https://doi.org/10.1007/s12187-019-09637-3

Wenjie Duan

duan.w@outlook.com

1 Social and Public Administration School, East China University of Science and Technology, Shanghai, People's Republic of China

2 Department of Sociology, Wuhan University, Wuhan, People's Republic of China

3 School of Philosophy, Zhongnan University of Economics and Law, Wuhan, People's Republic of China 